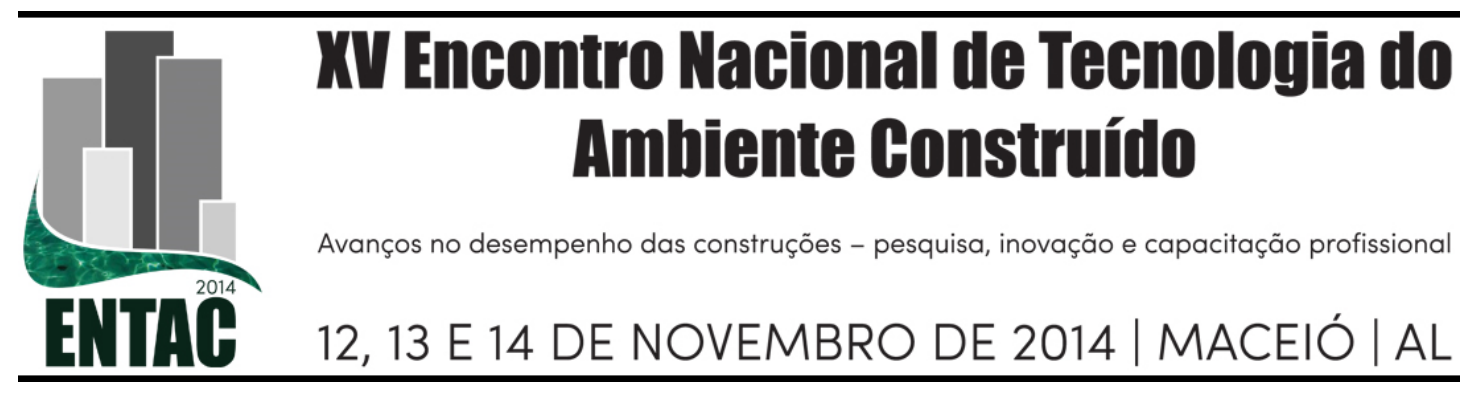

\title{
ANÁLISE DO PLANEJAMENTO DE MÉDIO E CURTO PRAZO NA CONSTRUÇÃO CIVIL: ESTUDO DE CASO EM UM EDIFÍCIO COMERCIAL
}

\author{
CAMPOS, Vanessa Ribeiro (1); BEZERRA, Diego de Moraes Duarte (2)
}

(1) Universidade Federal do Ceará, e-mail: vanessa.campos@ufc.br, (2) Universidade Federal do Ceará, e-mail: diegoduartebezerra@gmail.com

\begin{abstract}
RESUMO
Na indústria da construção civil, em especial o setor edificações percebem-se baixos índices de produtividade e elevados desperdícios de recursos. Em muitos casos, na busca de velocidade de finalização dos serviços é deixado de lado o controle do planejamento. O planejamento inadequado pode resultar em situações de insatisfação de clientes no tocante a prazos, atrasos injustificados, orçamentos ineficazes e desgaste da imagem da empresa. Nesse contexto, a pesquisa visa estudar as principais causas que levam ao atraso do cronograma do empreendimento por meio do estudo de caso em uma empresa de edificações em Fortaleza. O presente trabalho descreve o planejamento de curto e médio prazo da obra e faz uma avaliação do desempenho da obra em relação às reprogramações feitas e os desvios de prazos.
\end{abstract}

Palavras-chave: Planejamento e Controle da Produção, Construção Civil, Edificações.

\begin{abstract}
In construction industry, specifically the construction of buildings sector, there is a low level of production and high waste of resources. In many cases, to anticipate the projects execution, builders neglect planning and control. Insufficient planning can result in customer dissatisfaction regarding deadlines, unjustified delays, inefficient budget, and it compromises the company's image. Thus, this research aims to study the main causes that lead to the delay of a project, a case study of a building construction company situated in Fortaleza. This paper describes the short and medium term plan of the work and analysis its performance concerning the rescheduling plan and deadlines deviations.
\end{abstract}

Keywords: Production Planning and Control, Civil Construction, Building Construction.

\section{INTRODUÇÃO}

A indústria da construção civil, em especial o setor edificações, é frequentemente citada como exemplo de setor atrasado, no tocante ao cumprimento de prazo e custo, com baixos índices de produtividade e elevados desperdícios de recursos (SAURIN, FORMOSO, 2006). Em muitas situações, a busca por agilizar a obra faz com que seja deixado de lado o planejamento e controle da produção.

Em decorrência desse fato, surgem os atrasos e problemas que podem ser evitados com um bom planejamento do projeto e controle efetivo das unidades produtivas. Muitas obras são executadas sem planejamento de execução e sem a garantia do prazo previamente estabelecido, problema frequente em obras de pequeno porte e até mesmo de grande porte, que acabam comprometendo a qualidade final do serviço. 
Nesse sentido, foi realizado um estudo de caso do planejamento e controle da produção de uma obra na cidade de Fortaleza e analisados os desvios que ocorreram nos meses de abril a agosto para os serviços planejados e executados, por meio do acompanhamento do plano de curto e médio prazo. Foi feito um acompanhamento diário da produção e uma reprogramação mensal com a finalidade de identificar todas as restrições.

O presente trabalho descreve o planejamento de curto e médio prazo da obra como objeto de estudo e faz a avaliação do desempenho da obra em relação às reprogramações feitas no curto prazo e médio prazo e seus desvios. Os resultados da pesquisa demonstram a importância de avaliação do planejamento por meio da utilização de indicadores de desempenho e análise de restrições aplicadas na construção de edifícios. Por fim, os resultados refletem sobre a necessidade de um planejamento bem elaborado, antes e durante a execução de um empreendimento.

\section{PLANEJAMENTO E CONTROLE DA PRODUÇÃO}

Um departamento muito comum nas grandes construtoras é o de Planejamento e Controle da Produção (PCP), no qual viabiliza a realização de um processo organizado, produtivo, transparente e mais rentável. Slack et al. (2002) definem o PCP como sendo a atividade de se decidir sobre o melhor emprego dos recursos de produção, assegurando assim, a execução do que foi previsto no tempo e quantidade certa e com os recursos corretos, permitindo a continuidade dos processos.

Dentre as várias funções que do PCP, talvez, a mais significa é o acompanhamento da produção, pois é por meio dele que se monitora o avanço das atividades e se observa o cumprimento do cronograma ou se há variação entre o que foi previsto e o que foi realizado em campo.

O planejamento é um processo de tomada de decisão em que se idealizam as ações que ocorrem em determinado momento no futuro. No entendimento de Chiavenato (1990), na administração, se os serviços estiverem exatamente de acordo como foi planejado, não há necessidade do controle de produção.

Outro fato que é constatado, na indústria da construção civil, é a ausência ou ineficiência do planejamento e controle das obras. Há empresas que não planejam; outras que planejam, mas não o fazem bem e, quando o fazem, não controlam. Enquanto algumas construtoras se esforçam por gerar cronogramas detalhados, e aplicar programações semanais de serviço, outras acreditam que a experiência de seus profissionais é o suficiente para o cumprimento de prazo e custo.

Formoso (1991) considera o controle como parte inerente do processo de planejamento, e deve ser visto como um processo de tomada de decisão que envolve a atribuição de metas e dos procedimentos necessários para serem alcançados. O planejamento torna-se eficaz quando seguindo por um controle. Wiginescki (2009) ressalta a importância de se adotar procedimentos eficazes de controle no intuito de garantir os melhores resultados, reduzindo, assim, algumas incertezas.

\subsection{Níveis do planejamento}

O planejamento e controle da produção são, usualmente, divididos em duas dimensões: a horizontal (preparação, coleta de informações, elaboração dos planos, difusão das informações, ação e avaliação do processo) e a vertical (planejamentos de longo prazo, médio prazo e curto prazo). O presente estudo tem foco nas etapas da dimensão horizontal para o empreendimento analisado. 
A dimensão horizontal se refere às etapas pelas quais o processo de planejamento e controle é realizado, já a dimensão vertical define como as etapas são vinculadas entre os diferentes níveis gerenciais de uma organização. De acordo com Formoso (2001), essas etapas podem ser descritas como:

- Preparação do processo de planejamento - define os procedimentos utilizados na execução do planejamento, como: frequência de atualização dos planos, horizonte e nível de detalhes do planejamento e grau de centralização do controle. A preparação ocorre antes do início do empreendimento e, em épocas específicas, de forma intermitente. Esta etapa se concentra na tomada de decisões.

- Coleta de informações - consiste na obtenção de informações necessárias para a realização do planejamento ou reprogramação. Informações, essas, que são geradas por vários setores da empresa como os clientes, empreiteiros, consultores, projetistas e órgãos públicos que fazem parte do processo de planejamento e controle.

- Preparação dos planos - etapa central do ciclo e, talvez, a mais importante é responsável por gerar os planos de obra. Várias técnicas de controle de tempo são utilizadas nessa fase que definem o serviço a executar, como será executado, até quando será executado e o local que deve ser executado.

- Difusão de informações - tem como objetivo comunicar e orientar sobre as informações do plano da obra geradas na etapa anterior;

- Ação - Durante essa etapa o processo de produção é controlado e monitorado, e as informações geradas do controle são utilizadas para retroalimentar os planos e preparar relatórios sobre o desempenho da produção. Essa etapa fecha o ciclo contínuo do planejamento.

- Avaliação do processo de planejamento - última etapa que deve proporcionar melhorias ao processo de planejamento.

A última fase do ciclo, que corresponde à avaliação, é fundamental para garantir o controle eficaz do planejamento. Esse controle pode ser feito com o auxílio de indicadores demonstrados a seguir.

\subsection{Avaliação e Controle da Produção}

Ulubeyli, Kazaz e Er (2014) argumentam que há três elementos essenciais no planejamento de projetos de construção civil: tempo, custo e qualidade. Esses três conceitos estão intrinsecamente ligados com a produtividade do trabalho. A avaliação e o acompanhamento da produtividade de equipes de trabalho são instrumentos que garantem a eficácia dos elementos citados acima.

O controle na construção civil deve proporcionar melhorias ao processo de planejamento. Outro objetivo, salientado por Bernardes (2001), é evidenciar os problemas na produção que impedem o cumprimento das metas planejadas, a partir daí, deve-se eliminar a restrição e retroalimentar o planejamento. Para tanto, muitas construtoras utilizam indicadores de desempenho como apoio à tomada de decisões.

Os indicadores aplicados no estudo, para o plano de médio prazo, foram o IRR (Índice de Remoção de Restrições) e o DPO (Desvio de Prazo da Obra). Já no plano de curto prazo, foi usado um índice de Porcentagem de Pacotes Concluídos (PPC). Esses indicadores e seus objetivos são apresentados no Quadro 1. 
Quadro 1 - Indicadores de avaliação de processo

\begin{tabular}{|l|l|l|}
\hline \multicolumn{1}{|c|}{ NOME } & \multicolumn{1}{|c|}{ OBJETIVO } & PERIODICIDADE \\
\hline $\begin{array}{l}\text { PPC - PORCENTAGEM DE } \\
\text { PLANO CONCLUÍDO }\end{array}$ & $\begin{array}{l}\text { Avaliar a eficácia do planejamento } \\
\text { de curto prazo }\end{array}$ & Curto Prazo \\
\hline $\begin{array}{l}\text { IRR - ÍNDICE DE } \\
\text { REMOÇÃO DE } \\
\text { RESTRIÇÕES }\end{array}$ & $\begin{array}{l}\text { Identificar as remoções das } \\
\text { restrições identificadas. }\end{array}$ & Médio Prazo \\
\hline $\begin{array}{l}\text { DPO - DESVIO DE } \\
\text { PRAZO DA OBRA }\end{array}$ & $\begin{array}{l}\text { Identificar desvios de prazo da } \\
\text { obra. }\end{array}$ & $\begin{array}{l}\text { Médio e Longo } \\
\text { Prazo }\end{array}$ \\
\hline
\end{tabular}

O primeiro indicador corresponde a Porcentagem de Planos Concluídos (PPC) que é coletado, ao longo da obra, em períodos preestabelecidos. O seu cálculo é dado pelo quociente entre a quantidade de atividades planejadas e concluídas e a quantidade de atividades planejadas.

Em sequência, têm-se o Índice de Remoção de Restrições (IRR) que mostra o percentual de remoções e resulta do quociente entre a quantidade de restrições removidas na data prevista e a quantidade total de restrições identificadas.

O último indicador corresponde o Desvio de Prazo da Obra (DPO), que avalia o desempenho da obra finalizada, pela relação entre o prazo previsto e o prazo real, o prazo no qual a obra foi executada. O cálculo é dado pelo quociente da diferença entre o prazo real e o previsto pelo prazo previsto.

\section{ESTUDO DE CASO}

A empresa da pesquisa é de médio porte, situa-se na cidade de Fortaleza, e possui 25 anos de atuação em construção. A organização trabalha com obras para terceiros, atuando principalmente na edificação de empreendimentos comerciais e residenciais, no Estado do Ceará. Seu sistema de gestão da qualidade certificado com base nas normas ISO 9001:2000 e PBQP-H.

O empreendimento estudado consiste em uma obra vertical do tipo comercial, a empresa é a gerenciadora por meio da modalidade de contratação por administração. O acompanhamento do PCP foi feito desde ao planejamento, junto à empresa terceirizada responsável, até o controle da produção feito no canteiro de obra.

A pesquisa foi realizada por meio de consultas em relatórios e planilhas geradas pela empresa. O estudo de caso foi aplicado no acompanhamento do planejamento da obra nos meses de: abril, maio, junho, julho e agosto.

O acompanhamento do PCP foi feito desde o planejamento, junto à empresa, até o controle da produção no canteiro de obra. O planejamento é revisado mensalmente, e após a revisão, as informações, com a programação semanal, são transmitidas para equipe, de forma clara e, de fácil entendimento da equipe. O acompanhamento do processo de planejamento é feito com uso de indicadores conforme apresentados nos resultados da pesquisa. 


\section{RESULTADOS E DISCUSSÕES}

\subsection{Análise dos indicadores de desempenho}

A medição de desempenho da produtividade é a maneira de se visualizar com clareza o andamento dos processos de trabalho da empresa e, também, serve para apoiar à tomada de decisão. Uma vez coletados os dados, no final de cada mês, o IRR é calculado, cujo resultado está exposto na figura 1.

Figura 1 - Índice de Remoção de Restrições

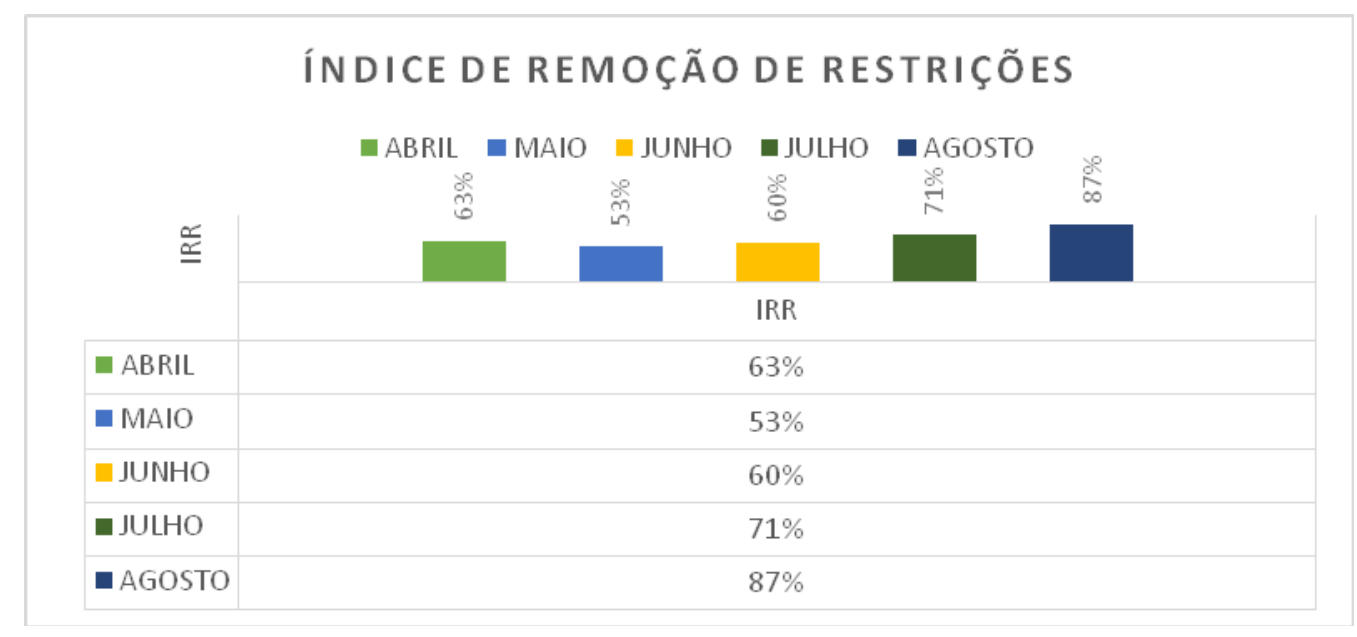

A mensuração do IRR foi resultado da análise das restrições do plano de médio prazo. Pode-se observar pela figura 1, que após o mês de maio, houve aumento o IRR, fato que pode ser explicado pelo maior número de restrições que interferem diretamente com o prazo da obra. Essas restrições foram assim, tratadas com um maior grau de prioridade. O IRR permite avaliar a eficácia do planejamento, pois analisa as remoções das restrições para o horizonte de planejamento utilizado no médio prazo.

Outro indicativo abordado foi o PPC (Porcentagem de Pacotes Concluídos), cujos dados foram coletados diariamente, e as informações com os resultados semanais eram repassadas para as equipes de trabalhos.

O PPC é mensurado semanalmente e pode ser visualizado pela figura 2, que mostra o acompanhamento durante a primeira semana de abril à última semana de agosto. Percebe-se a eficiência da obra em relação a reprogramação (barras azuis), e em relação ao planejamento do início do mês (barras vermelhas). 
Figura 2 - Porcentagem do plano concluído

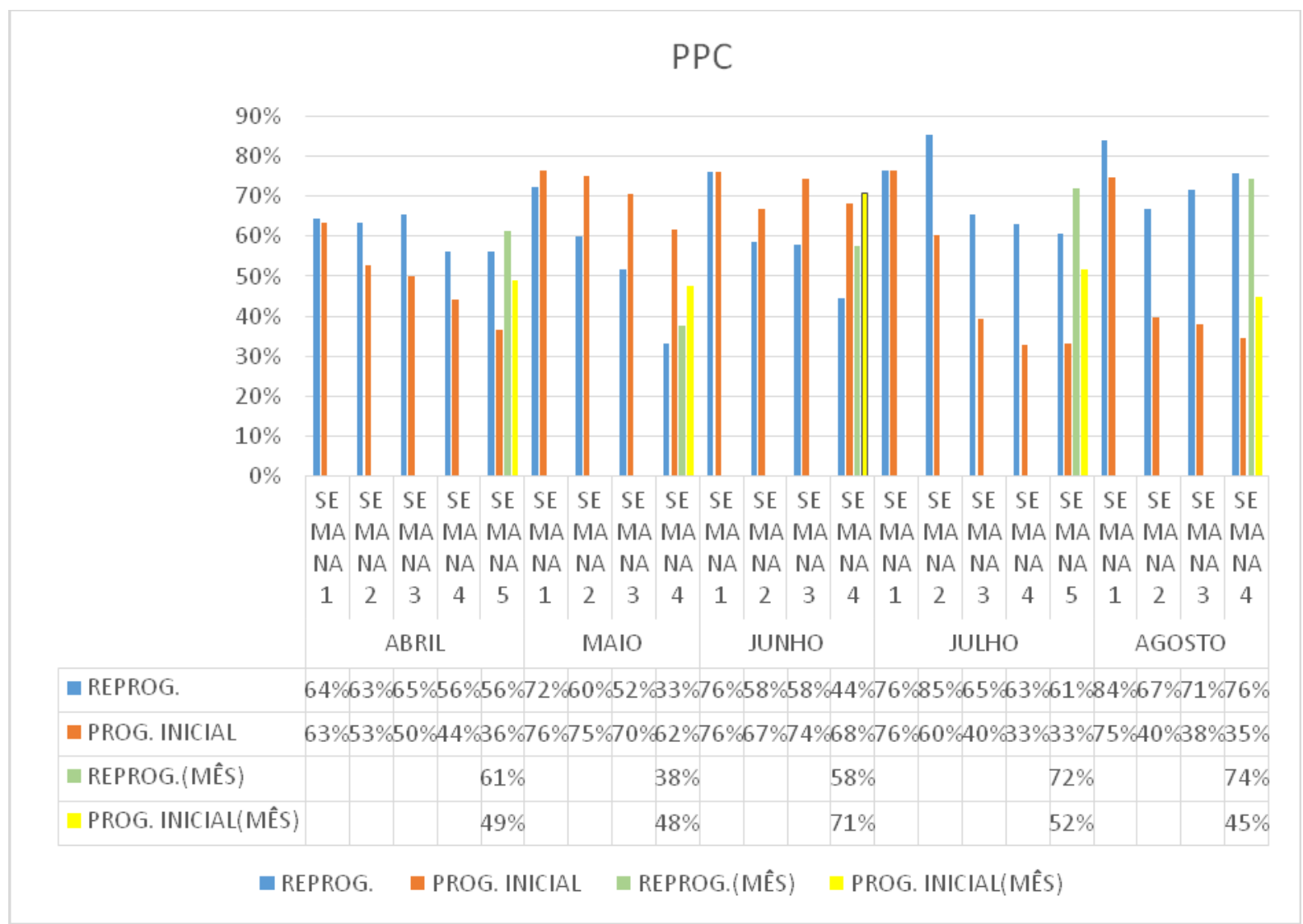

Verifica-se baixa eficiência no desempenho no plano de curto prazo, tanto nas metas estabelecidas no início do mês, como as metas semanais estipuladas pela equipe da obra. O PPC apresentou variação de $57 \%$ a $64 \%$, a reprogramação e programação inicial com desvios padrão de $12 \%$ a $17 \%$, respectivamente.

O desempenho da obra foi avaliado pela utilização do indicador DPO (Desvio de Prazo da Obra), que faz a relação entre o prazo previsto e prazo real. É importante observar que, devido a um atraso na instalação dos elevadores definitivos da obra, houve um adiamento na desmontagem dos elevadores e, consequentemente, retardou o serviço de revestimento da fachada (balanças 21 e 22).

Sabendo-se que esses serviços fazem parte do caminho crítico da obra, portanto impactam na data final de entrega, foi decidido realizar dois monitoramentos dos desvios de prazo da obra: um considerando o atraso na entrega do serviço das balanças 21 e 22 e outro sem esse serviço.

A figura 3 mostra os DPO's dos meses de abril, maio, junho, julho e agosto, em que foram calculados tendo como prazo real o prazo final projetado de acordo com o ritmo de andamento da obra no mês em questão e o prazo previsto.

Vale ressaltar, que muitos serviços não fazem parte do escopo do planejamento e muitas indefinições de projetos dificultando ainda mais a previsão de uma data real. 


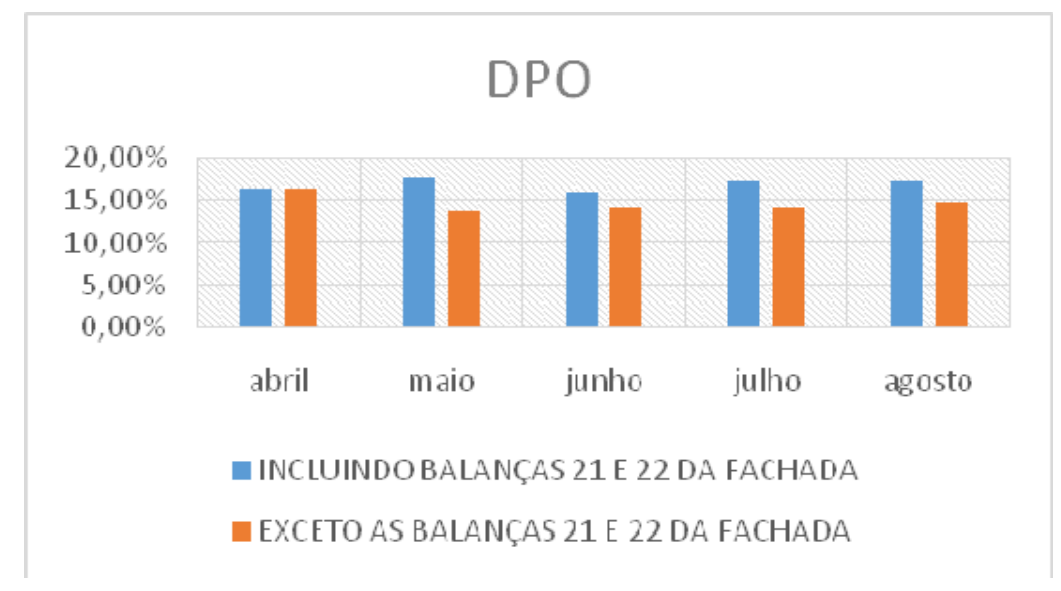

\subsection{Análise das reprogramações e causas}

Devido aos atrasos de alguns serviços, desde baixa produtividade a atraso de fornecedores, foi necessário reprogramar alguns serviços que, depois de feito o diagnóstico, foram atribuídas novas datas nas reuniões semanais de curto prazo. A forma usada para avaliar a eficácia, do processo de reprogramação das datas, de alguns serviços, foi o uso do indicador PPC (Percentagem do Plano Concluído), por meio de um paralelo entre o PPC da programação inicial com o PPC da reprogramação.

\section{Figura 4 - Porcentagem do Plano Concluído}

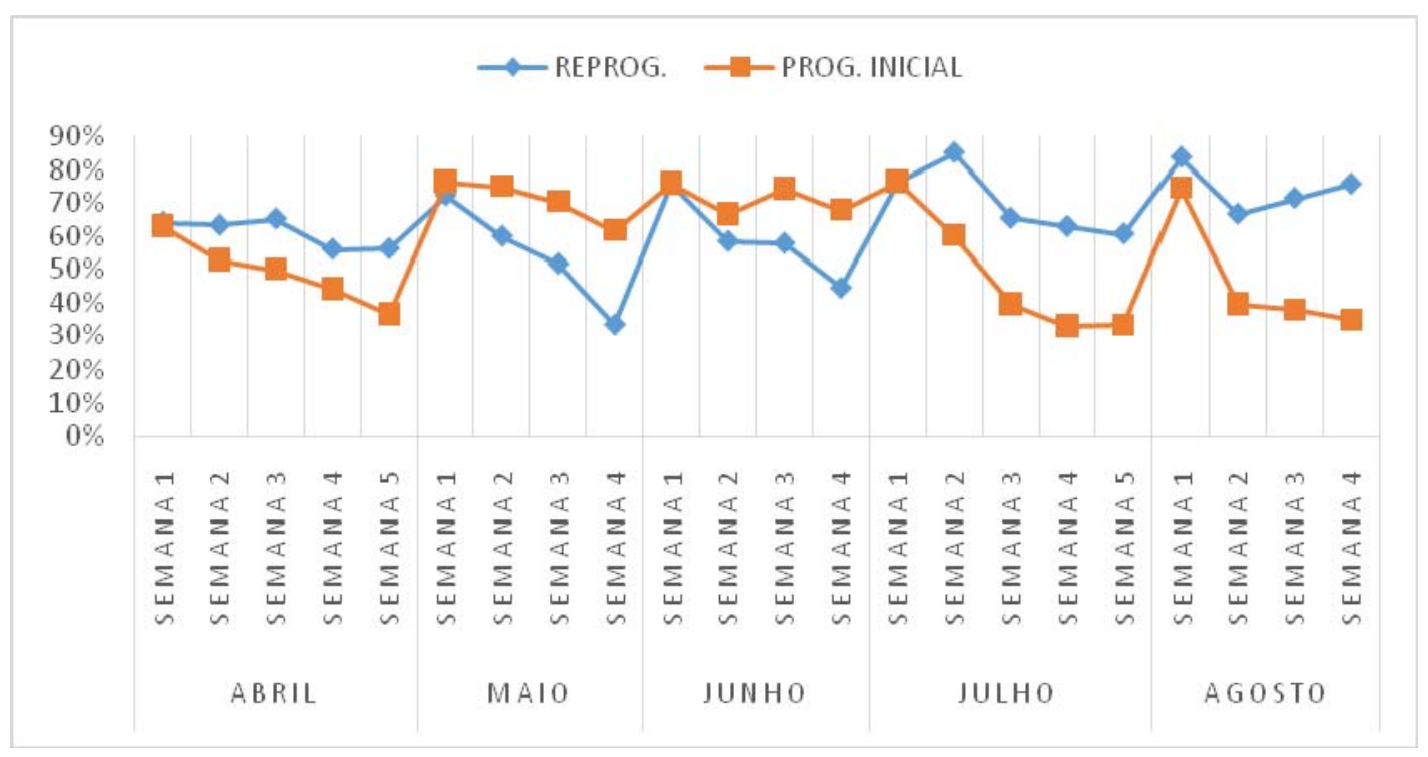

A figura 4, mostra que nos meses de maio e junho, as reprogramações dos serviços não ocorrem de forma eficiente. Essa discrepância, entre a programação inicial e a reprogramação, pode ser explicada pela busca em antecipar serviços, permitindo trazer o cronograma da obra o mais próximo possível da primeira data prevista.

É fundamental, para o controle do planejamento, avaliar os motivos que impedem a execução dos serviços planejados nos prazos previstos. Essas análises, de restrições ao cumprimento dos planos, foram discutidas em reuniões semanais com suas devidas 
ações corretivas, com a finalidade de minimizar o impacto, ou até mesmo eliminá-lo. Dessa forma, foi possível manter a data inicialmente prevista de entrega do empreendimento.

Foi elaborado um gráfico com a freqüência de ocorrência de causas de atrasos dos pacotes planejados. Os percentuais dos principais problemas detectados são mostrados na figura 5 que reflete o período de cinco meses.

Figura 5 - Porcentagem de causas (abril a agosto)

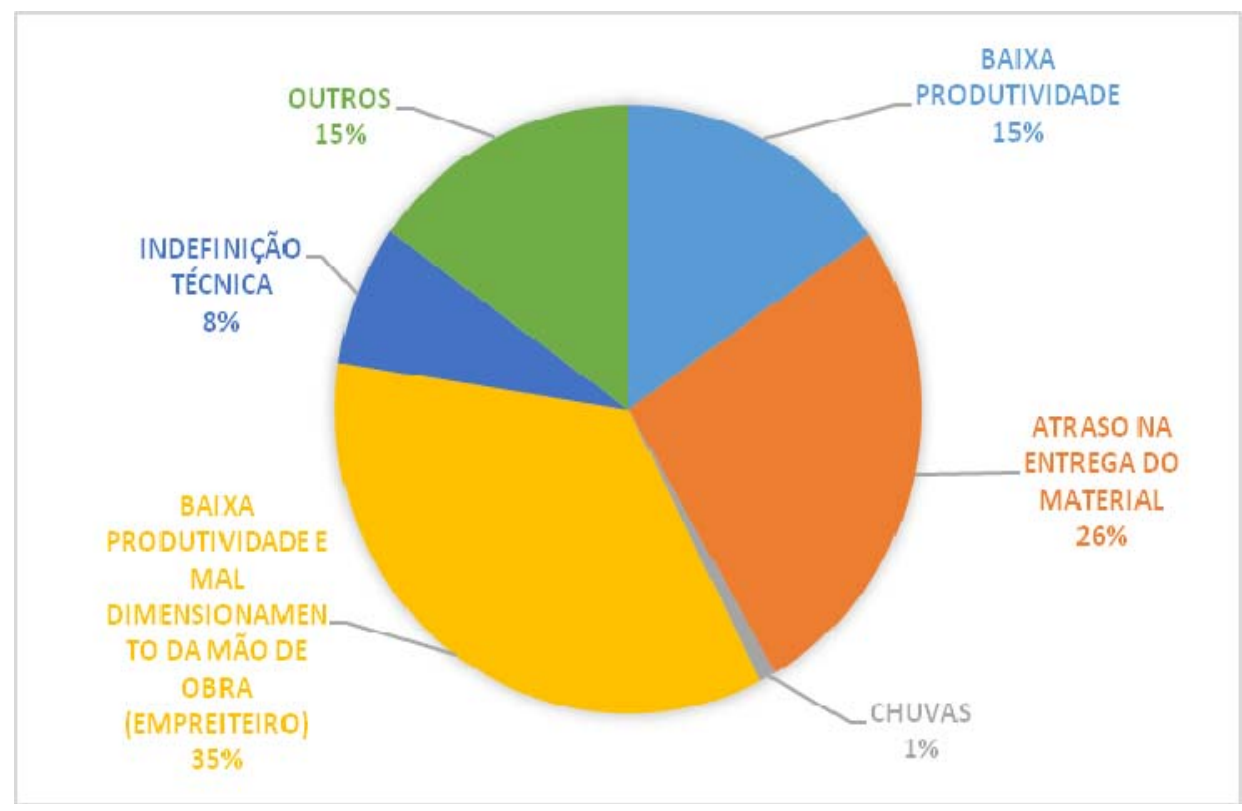

Foi observado que $61 \%$ das causas dos atrasos estão relacionados com as empresas que prestam serviços ou que fornecem materiais. Isso mostra a necessidade de avaliar criteriosamente as empresas parceiras para futuros empreendimentos. Uma possível solução consiste em incluir cláusulas no contrato multas por atrasos a essas empresas.

\section{CONSIDERAÇÕES FINAIS}

O presente trabalho indicou a importância das técnicas de controle do planejamento para construção de edifícios. As ferramentas servem de apoio à tomada de decisão no que concerne ao cumprimento de prazos e qualidade dos serviços em obras de edificações.

O estudo de caso mostrou que a obra lida com atrasos em seus serviços e, com isso, fica evidente a necessidade contínua de revisões no planejamento. Em consequência, percebe-se um acúmulo de serviços a serem executados. Para resolver tais questões e garantir a entrega da obra no prazo, seria necessário contratar mão de obra, resultando em custos adicionais para empresa. Foi possível verificar baixa eficiência no alcance das metas estabelecidas no médio prazo, e no curto prazo, a necessidade constante de reprogramações. Evidenciou-se, também, que as maiores causas dos atrasos, no plano de curto prazo, estão relacionadas com os serviços de terceiros, tanto pela prestação de serviço como no fornecimento de materiais.

A fim de melhorar o alcance de metas e a remoção de restrições, é preciso haver mudança comportamental nos integrantes envolvidos com o PCP, buscando maior qualidade na execução de projetos, maior empenho na remoção das restrições e maior comprometimento por parte das empresas contratadas. 


\section{REFERÊNCIAS}

BERNARDES, M. M. S. Desenvolvimento de um modelo de planejamento e controle da produção para micro e pequenas empresas da construção. 2001. $291 \mathrm{f}$. Tese (Doutorado em Engenharia Civil) - Universidade Federal do Rio Grande do Sul, Porto Alegre, 2001.

CHIAVENATO, I. Iniciação ao planejamento e controle da produção. São Paulo: Mc Graw - Hill, 1990.

FORMOSO, C. A knowledge based framework for planning house building projects. 1991. Tese de Doutorado. University of Salford - Departament of Quantity and Building Surveying, Salford.

Planejamento e controla da produção em empresas de construção. Universidade Federal do Rio Grande do Sul. Porto Alegre, 2001.

SAURIN, T. A.; FORMOSO, C. T. Planejamento de canteiros de obras e gestão de processos. HABITARE, Porto Alegre. 2006.

SLACK, N.; CHAMBERS, S. HARLAND, C.; HARRISON, A.; JOHNSTON, R. Administração da produção. 2 ed. São Paulo: Atlas, 2002.

ULUBEYLI, S.; KAZAZ, A.; ER, B. Planning Engineers' Estimates on Labor Productivity: Theory and Practice. Procedia - Social and Behavioral Sciences, v. 119, p. 12-19, 2014.

WIGINESCKI, Beatriz Becker. Aplicação dos princípios da construção enxuta em obras pequenas e de curto prazo: um estudo de caso. 2009. 155 f. Dissertação (Mestrado em Construção Civil) - Faculdade de Engenharia Civil, Universidade Federal do Paraná, Curitiba, 2009. 